\title{
LA GESTACIÓN POR SUSTITUCIÓN Y LAS OBLIGACIONES EMANADAS PARA LOS ESTADOS PARTE EN EL CONVENIO EUROPEO DE DERECHOS HUMANOS: REPERCUSIONES EN EL ORDENAMIENTO JURÍDICO ESPAÑOL DEL ACTIVISMO Y DE LA AUTOLIMITACIÓN JUDICIAL DEL TRIBUNAL EUROPEO DE DERECHOS HUMANOS EN RELACIÓN CON LA GESTACIÓN POR SUSTITUCIÓN
}

Gestational surrogacy and the obligations emanated for the States part in the European Convention on Human Rights: Implications on the Spanish legal order of activism and judicial self-restraint of the European Court of Human Rights at this regards

\section{DANIEL GARCÍA SAN JOSÉ \\ Universidad de Sevilla dagarcia@us.es}

Cómo citar/Citation García San José, D. (2018) La gestación por sustitución y las obligaciones emanadas para los Estados parte en el Convenio Europeo de Derechos Humanos: repercusiones en el ordenamiento jurídico español del activismo y de la autolimitación judicial del Tribunal Europeo de Derechos Humanos en relación

con la gestación por sustitución. Revista Española de Derecho Constitucional, 113, 103-130 doi: https://doi.org/10.18042/cepc/redc.113.04

\section{Resumen}

En este estudio se analiza la ratio decidendi desarrollada por el Tribunal Europeo de Derechos Humanos siguiendo una política de activismo y autolimitación judicial en recientes casos relativos a la gestación por sustitución (Labassee, Menesson, Foulon, Bouvet, Paradiso y Campanelli) para medir el alcance de las obligaciones 
internacionales asumidas por los Estados que, siendo parte en el Convenio Europeo de Derechos Humanos, no permiten la gestación por sustitución en sus territorios ni reconocen los efectos legales de esta cuando se realiza en el extranjero conforme al derecho de otro Estado. Se induce de dicho análisis que los nuevos modelos de familia y las relaciones filiales generadas por un contrato de gestación por sustitución encuentran protección en los derechos a la vida privada y familiar en el art. 8 del Convenio Europeo de Derechos Humanos, cuando se da un vínculo biológico entre las partes, pero no en ausencia de este.

\section{Palabras clave}

Gestación por sustitución; derechos fundamentales y nuevas técnicas de reproducción humana asistida; interpretación teleológica y aplicación efectiva del Convenio Europeo de Derechos Humanos; vida familiar de facto; doctrina de la proporcionalidad de injerencias y justo equilibrio de intereses en juego.

\section{Abstract}

In this paper is analyzed the ratio decidendi developed by the European Court of Human Rights, according to a dual approach of judicial activism and judicial self-restraint, in recent cases concerning gestational surrogacy (Labassee, Menesson, Foulon, Bouvet, Paradiso and Campanelli), to size the scope of the international obligations assumed by the States which are parties to the European Convention on Human Rights and they prohibit gestational surrogacy in their territories and abroad. This analysis allows us to conclude that new models of family and subsidiaries relationships generated by international surrogacy contracts are guaranteed in the rights to private and family life under art. 8 of the European Convention on Human Rights provided a biological link exists among the people concerned (father of intention and children so conceived).

\section{Keywords}

Gestational surrogacy; fundamental rights and new techniques of assisted human reproduction; family life de facto; teleological Interpretation and effective implementation of the European Convention on Human Rights; doctrine of the proportionality of interference and fair balance of Interests at stake. 


\section{SUMARIO}

I. INTRODUCCIÓN: LOS NUEVOS MODELOS DE FAMILIA Y LAS RELACIONES FILIALES GENERADAS POR UN CONTRATO DE GESTACIÓN POR SUSTITUCIÓN ¿̇ESTÁN GARANTIZADAS EN LOS DERECHOS A LA VIDA PRIVADA Y FAMILIAR PROTEGIDOS EN EL ARTÍCULO 8 DEL CONVENIO EUROPEO DE DERECHOS HUMANOS? II. LA JURISPRUDENCIA DEL TRIBUNAL EUROPEO DE DERECHOS HUMANOS EN LA MATERIA: 1. La interpretación teleológica del CEDH (noción de familia de facto a los efectos del Artículo 8.1) en los casos Labassee y Menesson c. Francia (2014), Foulon y Bouvet c. Francia (2016). 2. La interpretación restrictiva del CEDH (amplio margen de apreciación nacional a los efectos del artículo 8.2 en ausencia de vínculo biológico entre padre de intención y menor nacido por gestación sustitutoria) en el caso Paradiso y Campanelli c. Italia (2015, Sala y 2017, Gran Sala). III. REPERCUSIONES EN EL ORDENAMIENTO JURÍDICO ESPAÑOL DEL ACTIVISMO Y DE LA AUTOLIMITACIÓN JUDICIAL DEL TEDH EN RELACIÓN CON LA GESTACIÓN POR SUSTITUCIÓN. IV. CONCLUSIONES. BIBLIOGRAFía.

\section{INTRODUCCIÓN: LOS NUEVOS MODELOS DE FAMILIA Y LAS RELACIONES FILIALES GENERADAS POR UN CONTRATO DE GESTACIÓN POR SUSTITUCIÓN ¿ESTÁN GARANTIZADAS EN LOS DERECHOS A LA VIDA PRIVADA Y FAMILIAR PROTEGIDOS EN EL ARTÍCULO 8 DEL CONVENIO EUROPEO DE DERECHOS HUMANOS?}

Sí, lo están. Aun cuando no existieran dichas técnicas de reproducción asistida en el momento en que se firmó el Convenio Europeo de Derechos Humanos (en adelante, CEDH), el 4 de noviembre de $1950^{1}$, y por tanto referencias a la maternidad por sustitución no se encuentren ni en el CEDH ni en sus protocolos adicionales de contenido normativo, así se deduce de la interpretación que del mismo hace el Tribunal Europeo de Derechos Humanos (en adelante, TEDH) adaptándolo a las circunstancias de vida actuales para que los derechos reconocidos no sean ilusorios sino efectivos (Carrillo Salcedo, 2003: 105). El TEDH no es un legislador internacional y no puede suplir la inexistente regulación internacional sobre gestación sustitutoria, ni tampoco cuestionar las diferentes aproximaciones normativas de los Estados

1 España lo firmó el 24 de noviembre de 1977 y lo ratificó el 4 de octubre de 1979 (BOE núm. 243, de 10 de octubre de 1979; núm. 155, de 30 de junio de 1981 y núm. 234, de 6 de mayo de 1999). 
europeos con respecto a esta cuestión ${ }^{2}$. Los contratos privados de gestación por sustitución celebrados en el extranjero son una realidad y el derecho, como herramienta reguladora de las acciones sociales, debe asumir una postura $^{3}$ ante los problemas jurídicos de la gestación por sustitución — no solo desde el punto del derecho civil y de la filiación-, sino especialmente desde consideraciones éticas (Selma Penalva, 2014: 1-12), que no se resuelven dejando las cosas como están (Davis, 2012: 144).

Lo que sí hace el TEDH es aplicar el art. 1 del CEDH, garantizando el efectivo disfrute de los derechos reconocidos a cualquier persona que se encuentre dependiente de la jurisdicción de un Estado parte en el $\mathrm{CEDH}^{4}$ —a los efectos de este artículo, el derecho al respeto de la vida privada y familiar del menor nacido en el extranjero mediante contrato de gestación por sustitución-, siguiendo una bien conocida técnica complementaria de activismo y autolimitación judicial (Mahoney, 1990: 57-88) que, en el caso de la gestación por sustitución, se articula sobre la base del reconocimiento de un amplio margen de apreciación a las autoridades nacionales para adoptar decisiones por razones de orden público que afecten a particulares (por ejemplo, la negativa a

2 La regulación de la gestación por sustitución en Europa puede calificarse como de «normatividad de geometría variable». Geometría, en primer lugar, por cuanto las posibles aproximaciones normativas a esta cuestión son, respectivamente, la permisión, la restricción, la prohibición y la no regulación. Variable, además, por cuanto las combinaciones de las aproximaciones normativas a nivel nacional se multiplican en función de que se distinga en nuestra comparativa la posición de los Estados en relación con la gestación por sustitución o respecto de las consecuencias jurídicas para las partes implicadas en este tipo de prácticas. Así, por ejemplo, un Estado puede no permitir la gestación por sustitución en su territorio al tiempo que permite regularizar a sus nacionales las relaciones parentales-filiales derivadas de una gestación por sustitución realizada en el extranjero. "Confer The Parentage/Surrogacy Project», preparado por un grupo de expertos en el seno de la Conferencia de La Haya de Derecho Internacional Privado, cuyo informe más reciente, de febrero de 2017 está disponible en https://bit.ly/2k0phtT (última consulta: 1 de octubre de 2017).

3 A pesar de la complejidad de la tarea, motivada en gran medida por la tensión dialéctica entre los condicionantes éticos y económicos en juego además de por la presencia distorsionadora de distintos sujetos y actores internacionales: Estados, organizaciones internacionales, empresas con ánimo de lucro, personas particulares con muy desigual estatus social y económico que participan en los contratos de gestación por sustitución, organizaciones no gubernamentales, etc. (Rodríguez-Yong y Martínez, 2010: 80).

4 «Artículo 1. Obligación de respetar los derechos humanos: Las Altas Partes contratantes reconocen a toda persona dependiente de su jurisdicción los derechos y libertades reconocidos en el Título I del Presente Convenio». 
inscribir en el Registro Civil un certificado de nacimiento otorgado en el extranjero en el que un contrato de gestación por sustitución es legal).Tales medidas, sin embargo, pueden constituir una violación del CEDH si no respetan un justo equilibrio entre los intereses en juego (en concreto, el derecho a la identidad y al establecimiento de una relación de filiación legal entre un menor nacido en el extranjero mediante un contrato de gestación por sustitución y su padre de intención cuando les une un vínculo biológico). Como han escrito Calvo Caravaca y Carrascosa González (2017: 109), en este tema «no se trata de que el TEDH obligue a los Estados parte en el CEDH a aceptar una filiación acreditada en el extranjero tras una gestación por sustitución aunque vulnere el orden público de dichos Estados sino que, como indica el TEDH, sólo tal admisión de tal filiación en el Estado de destino permite proteger el interés del menor, su vida privada y su identidad».

La jurisprudencia del TEDH relativa a los derechos reconocidos en el art. 8 del CEDH a particulares en el contexto de la gestación por sustitución hasta la fecha no ha afectado directamente a España — no le alcanza el efecto de res iudicata inter partes-, pero sí le concierne de manera indirecta, en cuanto queda sometida al efecto de res interpretata erga omnes de la ratio decidendi de las mismas (Carrillo Salcedo, 2003: 63). El propio art. 10.2 de la Constitución aporta las claves de la relevancia de la jurisprudencia del Tribunal Europeo en materia de gestación por sustitución para las autoridades españolas, pues una interpretación sistemática de nuestro texto constitucional exige tener presente, junto a los acuerdos internacionales en materia de derechos humanos, las decisiones emanadas de los órganos de garantía previstos en los mismos, en especial si son de carácter jurisdiccional, como es el caso del Tribunal Europeo de Derechos Humanos (Saiz Arnaiz, 1999: 210-211)5. En este sentido, obvia decir que todas las autoridades del Estado español —en especial las autoridades judiciales- deben conocer y respetar la ratio decidendi del TEDH en los significativos casos relativos a contratos de gestación por sustitución decididos hasta la fecha.

\section{LA JURISPRUDENCIA DEL TRIBUNAL EUROPEO DE DERECHOS HUMANOS (TEDH) EN LA MATERIA}

Carrillo Salcedo (2003: 91-110), antiguo magistrado del TEDH, analizó en su curso sobre el CEDH la lógica interna de activismo y autolimitación

5 Citando amplia jurisprudencia del Tribunal Constitucional: STC 30/1981, FJ 3; STC 101/1984, FJ 2; STC 120/1990, FJ 3; STC 36/1991, FJ 5; STC 341/1993, FJ 5; STC 50/1995, FJ 4; STC 140/1995, FJ 6; STC 21/1997, FJ 2. 
judicial que caracteriza desde sus comienzos a la jurisprudencia de este órgano jurisdiccional internacional: por un lado, se trata de un tratado internacional de protección de derechos humanos y, por tanto, el TEDH debe asegurarse de la protección real y efectiva, no ilusoria, de los mismos, tomando en consideración las condiciones de vida actuales y nuevos modos en los que el disfrute de dichos derechos puede ser impedido, aun cuando no estuvieran previstos originariamente (interpretación teleológica o províctima). Por otra parte, sin embargo, al ser un tratado internacional en el que son parte 47 Estados europeos muy distintos entre sí, es necesario respetar las particularidades de cada uno de ellos a la hora de cumplir sus obligaciones con el mismo, en particular estando en juego cuestiones moralmente sensibles respecto de las cuales aún no existe un consenso europeo y tratándose de derechos como los reconocidos en los arts. 8 a 11 del CEDH, que permiten restricciones en su ejercicio. De hecho, como se ha señalado por parte de la doctrina autorizada (Farnós Amorós, 2015: 177), es notable el ámbito de diversidad en el derecho de familia en Europa, con consecuencias previsibles en la jurisprudencia del TEDH en la materia: la imposibilidad de identificar un case-law coherente en materia de acceso a la reproducción asistida por parte de los ciudadanos de los Estados parte en el CEDH (Farnós Amorós, 2015: 197). Véanse las sentencias del TEDH en los casos Evans c. Reino Unido, Dickson c. Reino Unido, S. H. y otros c. Austria, Costa y Pavan c. Italia, Parrillo c. Italia, entre otras.

\section{LA INTERPRETACIÓN TELEOLÓGICA DEL CEDH (NOCIÓN DE FAMILIA DE FACTO A LOS EFECTOS DEL ARTÍCULO 8.1) EN LOS CASOS LABASSEE Y MENESSON C. FRANCIA (2014), FOULON Y BOUVET C. FRANCIA (2016)}

Los cuatro casos de referencia son muy similares en cuanto a sus hechos, pero es posible presentarlos cronológicamente distinguiendo, de una parte, los casos Labassee y Menesson, resueltos en dos sentencias dictadas el 26 de junio de 2014 por el TEDH, y de otra parte, los casos Foulon y Bouvet, sobre los que el TEDH decidió conjuntamente el 21 de julio de 2016, dos años después de haber dictado la sentencia condenatoria de Francia por hechos muy similares ${ }^{6}$.

6 La jurisprudencia del TEDH citada en este trabajo ha sido consultada en la web oficial del Tribunal Europeo: https://hudoc.echr.coe.int (última consulta:1 de octubre de 2017). Esta web no será indicada en cada una de las referencias del TEDH que se citan en este trabajo, sino solo su número de demanda para su fácil localización en la citada web. 
En los casos Labassee y Menesson c. Francia, dos matrimonios de nacionalidad francesa, no pudiendo tener hijos por causa de infertilidad de la mujer, acudieron a los servicios de una empresa de gestación por sustitución en California, donando los varones sus gametos y usando óvulos de una donante anónima que fue fecundado e implantado en una madre gestante. Como resultado del proceso, nacieron dos gemelas para los Mennesson y una nińa para los Labassee. El Tribunal Supremo de California declaró la paternidad legal de los padres de intención con el consentimiento de todas las partes implicadas y al acudir al Consulado francés en Los Ángeles solicitando la transcripción del acta de nacimiento y la inscripción de las niñas en sus pasaportes para poder entrar con ellas en Francia, sendos matrimonios recibieron por respuesta una negativa de las autoridades consulares al sospechar que estaban ante dos casos de gestación por sustitución prohibido por la legislación gala. Con pasaporte norteamericano para las niñas y francés de los progenitores, regresaron a Francia e iniciaron un proceso judicial sin éxito antes de acudir al TEDH. El 26 de junio de 2014, el TEDH resolvió, por unanimidad, ambos casos declarando que Francia era responsable de una violación del art. 8 del Convenio al no haber permitido que los demandantes pudieran inscribir en el Registro Civil a sus hijas nacidas mediante un contrato privado de gestación por sustitución que habían celebrado en California.

En su razonamiento el TEDH comenzó recordando lo ya reiterado con anterioridad ${ }^{7}$ : para garantizar el derecho al respeto a la vida privada y familiar, el art. 8 del Convenio Europeo de Derechos Humanos presupone la existencia de una familia, pudiendo ser los vínculos familiares de facto. Esta situación se daba en ambos casos, a juicio del TEDH, pues reconoció que tanto los Mennesson como los Labassee se ocuparon de sus hijos como padres desde su nacimiento, viviendo de un modo que en nada se distinguía de la vida familiar en su acepción habitual ${ }^{8}$. Tras constatar que el art. 8 del Convenio entraba en juego, procedió a valorar si la injerencia en los derechos reconocidos en dicho artículo, el derecho al respeto de la vida familiar y el derecho al respeto de la vida privada, era o no conforme a lo que exige el párrafo segundo de dicho artículo: que sea una injerencia prevista en la ley, que persiga un fin legítimo en una sociedad democrática y que se respete una relación de proporcionalidad entre el fin perseguido y la injerencia sufrida por el particular en el ejercicio de sus derechos.

Por ejemplo, lo afirmado en su sentencia de 6 de octubre de 2011, en el caso Wagner y J.M.W.L. c. Luxemburgo, demanda núm. 43490/08, párr. 117.

8 Párr. 45 de la STEDH de 26 de junio de 2014 en el caso Mennesson c. Francia; demanda núm. 65192/11, párr. 81 de la STEDH de 26 de junio de 2014, en el caso Labassee c. Francia, demanda núm. 65941/11. 
Para constatar la proporcionalidad de la injerencia, el TEDH sopesa una serie de circunstancias en cada caso que conoce, a fin de reconocer un mayor o menor margen de apreciación a los Estados, estableciendo el siguiente silogismo: cuando un amplio margen de apreciación debe ser reconocido a los Estados, el TEDH debe mostrar una autolimitación judicial no pretendiendo sustituir a la autoridades nacionales en la valoración de las medidas adoptadas en una sociedad democrática para alcanzar el fin legítimo perseguido. Por el contrario, cuando a la luz de los factores relevantes del caso el TEDH entiende que debe reconocer un margen de apreciación nacional reducido, la conclusión es al contrario: procede a mostrar un activismo judicial províctima de la injerencia en el ejercicio de los derechos reconocidos, de manera que solo razones particularmente relevantes serán suficientes para justificar la compatibilidad de la injerencia con las obligaciones derivadas del Convenio.

En los casos Labassee y Mennesson c. Francia, el TEDH comenzó recordando la falta de consenso en la materia, lo cual abogaba en principio por reconocer un amplio margen de apreciación nacional a las autoridades francesas $^{9}$ (Iliadou 2017: 10). Sin embargo, el TEDH valoró la naturaleza del derecho en juego y su importancia para los particulares afectados por la injerencia. A tal fin, el TEDH distinguió la situación de los padres de la de los hijos. Así, en el supuesto de los padres, la injerencia sufrida estaría justificada por las razones de orden público invocadas por las autoridades francesas, pues, aunque implicaba una serie de consecuencias negativas para su vida diaria, no les impedía en ningún caso el establecimiento de una vida familiar. Las dificultades no eran insuperables y podían vivir en condiciones equiparables a las que viven otras familias ${ }^{10}$. En cambio, tratándose de las hijas, al estar en juego un aspecto esencial de su identidad cuando está afectada la filiación, el margen de apreciación debe reducirse considerablemente hasta el punto de que el TEDH llegó a considerar que no estaba justificada la injerencia sufrida por las hijas ${ }^{11}$. En efecto, respecto de la situación de las hijas — en conexión con la injerencia sufrida en su derecho al respeto de su vida privada-, el TEDH entendió que el respeto de este derecho se vincula con la esencia de la identidad, incluyendo

9 Párr. 45 de la STEDH de 26 de junio de 2014 en el caso Mennesson c. Francia, demanda núm. 65192/11, párr. 81 de la STEDH de 26 de junio de 2014, en el caso Labassee c. Francia, demanda núm. 65941/11.

10 Párrs. 78 y 79 de la STEDH de 26 de junio de 2014 en el caso Mennesson c. Francia, demanda núm. 65192/11.

11 Párrs. 96 a 98 de la STEDH de 26 de junio de 2014 en el caso Mennesson c. Francia, demanda núm. 65192/11. Párrs. 79 a 81 de la STEDH de 26 de junio de 2014, en el caso Labassee c. Francia, demanda núm. 65941/11. 
su filiación, la cual se había visto afectada de manera significativa en ambos casos. Recordando que en ambos casos el donante de gametos masculino era el padre de intención, el TEDH declaró que la paternidad biológica forma parte de la identidad del individuo, de manera que la prohibición de la gestación por sustitución existente en un Estado parte en el Convenio no puede provocar el desconocimiento de su filiación y así proyectarse sobre la identidad de las niñas, a las que se sitúa en una situación de incertidumbre jurídica sobre su identidad. Lo mismo ocurría con el derecho a la nacionalidad en la medida en que la nacionalidad constituye un elemento de la identidad de las personas ${ }^{12}$.

Con posterioridad a las sentencias dictadas en los casos Labassee y Menesson c. Francia, el Tribunal de Casación de ese país dictó dos sentencias con fecha de 3 de julio de 2015, en virtud de las cuales admitía la posibilidad de establecer el vínculo de filiación entre un menor y su padre biológico cuando se diera un supuesto de gestación por sustitución conforme a derecho en el país donde hubiera tenido lugar ${ }^{13}$. En virtud de esas sentencias, se remitió una circular a las fiscalías implicadas en casos similares - y que llegaron al TEDH (caso Foulon y Bouvet c. Francia) ${ }^{14}$ - en la que se les indicaba la conveniencia - pero no la obligación — de proceder a la transcripción de los certificados de nacimiento extranjeros de niños nacidos fuera de Francia mediante un contrato privado de gestación por sustitución, a reserva de la conformidad con el art. 47 del Código Civil francés ${ }^{15}$. Al conocer de las quejas planteadas por unos padres cuyos derechos de inscripción en el Registro Civil francés se les negaba por las mismas razones que en el caso de los Labassee y Menesson, el

12 Párrs. 100 a 102 de la STEDH de 26 de junio de 2014 en el caso Mennesson c. Francia, demanda núm. 65192/11. Párrs. 79 a 81 de la STEDH de 26 de junio de 2014, en el caso Labassee c. Francia, demanda núm. 65941/11.

13 Como se recoge en el párr. 36 de la STEDH de 21 de julio de 2016, en el caso Foulon y Bouvet c. Francia (demandas núm. 9063/14 y 10410/14): «Habiendo constatado que el certificado de nacimiento no era irregular ni había sido falsificado y que los hechos en el mismo recogidos reflejaban la realidad, el Tribunal de Apelación había deducido conforme a derecho que el contrato de gestación por sustitución [...] no suponía un obstáculo para la inscripción de la partida de nacimiento» (la traducción del original en francés es nuestra).

14 Los hechos son muy similares a los que motivaron los casos Labassee y Menesson c. Francia. Se trataba de una niña y de dos gemelos, respectivamente, nacidos en India mediante un contrato de gestación por sustitución por padres de intención con los que tenían un vínculo biológico.

15 Esto es, la solución que daba el ordenamiento francés a los menores solicitantes del establecimiento de su vínculo de filiación legal con su padre biológico era el reconocimiento de la paternidad o de la posesión del estado. 
TEDH volvió a condenar a Francia por una violación del art. 8 del CEDH en el caso Foulon y Bouvet c. Francia, al considerar que el carácter hipotético de la fórmula utilizada por el Gobierno demandado para las familias afectadas no era suficiente como para decidir de modo distinto a lo ya acordado en los casos Labassee y Menesson c. Francia ${ }^{16}$.

El rasgo común a estas sentencias del TEDH, además del Estado demandado, se encuentra en el hecho de que se daba un vínculo biológico entre los menores y padres de intención concernidos. Ahora bien, en la gestación por sustitución no siempre se da dicho vínculo biológico entre los padres de intención y el menor así concebido. ¿Serían aplicables los principios enunciados por el TEDH en las sentencias dictadas en los casos Labassee y Mennesson y Foulon y Bouvet a otros supuestos en los que faltara dicho vínculo biológico? La sentencia dictada en Sala por el TEDH en el caso Paradiso y Campanelli c. Italia el 27 de enero de 2015 parecía ofrecer una respuesta afirmativa a esta pregunta. Sin embargo, a la luz de la reciente sentencia dictada el 24 de enero de 2017 por la Gran Sala del TEDH al conocer del caso en apelación de conformidad con el art. 43 del CEDH, la respuesta es negativa, lo cual es explicable desde la lógica ya señalada, de activismo y autolimitación judicial que sigue este tribunal al interpretar y aplicar este instrumento internacional de protección de los derechos humanos.

\section{LA INTERPRETACIÓN RESTRICTIVA DEL CEDH (AMPLIO MARGEN DE APRECIACIÓN NACIONAL A LOS EFECTOS DEL ARTÍCULO 8.2 EN AUSENCIA DE VÍNCULO BIOLÓGICO ENTRE PADRE DE INTENCIÓN Y MENOR NACIDO POR GESTACIÓN SUSTITUTORIA) EN EL CASO PARADISO Y CAMPANELI C. ITALIA (2015, SALA Y 2017, GRAN SALA)}

Como ya se ha indicado, a diferencia de los casos antes citados, en el caso Paradiso y Campanelli c. Italia no existía un vínculo biológico entre ninguno de los padres de intención y el niño nacido mediante un contrato de gestación por

16 Párr. 56 de la STEDH de 21 de julio de 2016, en el caso Foulon y Bouvet c. Francia (demandas núm. 9063/14 y 10410/14). Resultaba particularmente molesto para el TEDH el hecho de que quedaba en manos de los fiscales en los casos competentes promover o no un recurso de apelación ante el Tribunal de Casación, pese a lo afirmado por este en sus sentencias de 3 de julio de 2015, relativas a las familias Labassee y Menesson. Más aún, a falta de un cambio en la legislación francesa, es evidente que el problema persistiría cuando los padres de intención figuren en el certificado de nacimiento sin tener un vínculo biológico con el menor nacido mediante este tipo de contratos. 
sustitución concluido por estos y una empresa en Rusia. En opinión del TEDH, conociendo en formación de Sala sobre el caso, la existencia o no de vida familiar es esencialmente una cuestión fáctica que dependerá de la existencia real en la práctica de estrechos lazos personales. A mayor abundamiento, la noción de «familia» en el art. 8 no está confinada solo a relaciones basadas en un matrimonio, pudiendo comprender otros "vínculos familiares» de facto cuando las partes están viviendo juntas fuera de un matrimonio y la relación tiene suficiente consistencia ${ }^{17}$. Aun cuando el art. 8 del CEDH no garantiza ni el derecho a fundar una familia ni el derecho a adoptar, el derecho al respeto de la vida familiar reconocido en dicho artículo- presupone la existencia de una familia, o al menos la relación potencial entre un menor y unos adultos, que surge, por ejemplo, de un genuino matrimonio incluso si la vida familiar no ha sido aún plenamente establecida o la relación que surge de una adopción legal. Recordó, en este sentido, el caso Moretti y Benedetti c. Italia relativo a un matrimonio (los demandantes) que habían aceptado acoger dentro de su familia a una niña de un año de edad. Aun cuando solo estuvieron diecinueve meses con ella hasta que los tribunales italianos decidieron entregarla a otra familia en adopción, el TEDH concluyó en dicho caso que existió una vida familiar de facto ${ }^{18}$.

Para la Sala del TEDH existía una familia de facto en el caso Paradiso y Campanelli c. Italia, entre otras razones considerando que los demandantes habían compartido con el niño las primeras importantes etapas de su joven vida: seis meses en Italia, desde el tercer mes de vida de este. Antes de ese período, el primer demandante había pasado varias semanas junto al nińo en Rusia. Aunque ese período fuera en sí mismo relativamente corto, el tribunal consideró que los demandantes habían actuado como padres con el niño y concluyó que existía una vida familiar de facto entre ellos ${ }^{19}$. Es de especial importancia que en el párr. 70 de su sentencia expresamente constatase que no

17 Párr. 67 de la sentencia del TEDH de 27 de enero de 2015 (Sala) en el caso Paradiso y Campanelli contra Italia, demanda núm. 25358/12. Véase la jurisprudencia citada en la misma a este respecto: caso Kroon y Otros c. Holanda, STEDH de 27 de octubre de 1994, demanda núm. 18535/91, párr. 30; caso Johnston y Otros c. Irlanda, STEDH de 18 de diciembre de 1986, demanda núm. 9697/82, párr. 55; caso Keegan c. Irlanda, STEDH de 18 de diciembre de 1986, demanda núm. 28867/03, párr. 44; caso $X, Y y$ $Z$ c. Reino Unido, STEDH de 22 de abril de 1997, demanda núm. 21830/93, párr. 36.

18 STEDH de 27 de enero de 2015 (Sala) en el caso Paradiso y Campanelli c. Italia, demanda núm. 25358/12, párr. 68. caso Moretti y Benedetti c. Italia, STEDH de 27 de abril de 2010, demanda núm. 16318/07, párr. 50 a 52.

19 Caso Paradiso y Campanellic. Italia, STEDH de 27 de enero de 2015 (Sala), demanda núm. 25358/12, párr. 69. 
existía una relación genética entre el segundo demandante y el niño. Aun así, la Sala del TEDH reiteró que el art. 8 protege no solo la vida familiar, sino también la vida privada. Esto incluye, hasta cierto punto, el derecho a establecer relaciones con otros ${ }^{20}$. A mayor abundamiento, la Sala del TEDH expresó la opinión de que no existían razones para creer que la noción de vida privada debiera ser usada en el sentido de excluir la determinación de una relación legal o biológica entre un nińo nacido fuera del matrimonio y su padre natural, habida cuenta de que el TEDH ha venido sosteniendo que el respeto de la vida privada exige que cada uno sea capaz de establecer detalles de su identidad como ser humano y que esa información es de importancia para el individuo a causa de sus implicaciones para su personalidad ${ }^{21}$.

Tras haber constatado la aplicación del art. 8 del Convenio a las circunstancias del caso, pues se daban unos vínculos familiares de facto entre los padres de intención y el niño nacido en Rusia pese a no existir vínculo biológico entre ellos, el TEDH procedió a examinar si la injerencia de las autoridades italianas podía ser constitutiva de una violación de los derechos reconocidos a los demandantes en dicho art. 8 del Convenio. Como es sabido, las injerencias en los arts. 8 a 11 del Convenio deben superar los requisitos previsto en el párr. segundo común a dichos artículos: ser una injerencia prevista en la ley, perseguir un fin legítimo y ser una injerencia necesaria en una sociedad democrática, lo que implica el respetar un justo equilibrio entre los distintos intereses en juego: esto es, entre los derechos de los demandantes y entre los fines perseguidos por las autoridades nacionales y los medios empleados para conseguirlos.

Para resolver en el presente caso la cuestión relativa a si la aplicación de la ley por las autoridades italianas respetó un justo equilibrio entre el interés público y los intereses privados en juego, el TEDH asumió que debía considerar el principio esencial según el cual siempre que estuviera en juego la situación de un niño, lo principal ha de ser salvaguardar el interés superior del

20 Como ya señaló, por ejemplo, en el caso Niemitz c. Alemania, STEDH de 16 de diciembre de 1992, demanda núm. 13710/88, párr. 29.

21 Véase el caso Gaskin c. Reino Unido, STEDH de 7 de julio de 1989, demanda núm. 10454/83, párr. 39. En el caso Paradiso y Campanelli contra Italia (demanda núm. 25358/12), el segundo demandante perseguía establecer, por sentencia judicial, que era padre natural del nińo. Esta solicitud de reconocimiento de su paternidad había sido legalmente establecida en Rusia, pero en Italia se condicionó a un test de identidad biológica, buscando descubrir si existía o no un vínculo biológico con el niño. El test dio negativo. Sin embargo, en opinión del TEDH existía un vínculo directo entre el establecimiento de la paternidad y el derecho a la vida privada del segundo demandante, con lo cual el art. 8 del Convenio entraba en consideración. 
menor $^{22}$. Así, aun cuando había quedado establecido que el padre de intención no tenía vínculo genético alguno con el niño gestado mediante un contrato de sustitución ${ }^{23}$, la aplicación de la ley italiana produjo como resultado el no reconocimiento de la relación de parentesco legal establecida en el extranjero debido a que los demandantes no tenían ningún vínculo biológico con el niño y, en este sentido, la Sala del TEDH consideró que los tribunales nacionales no actuaron de manera irrazonable al aplicar estrictamente la ley para determinar la paternidad y al ignorar el estatus legal establecido en el extranjero ${ }^{24}$. Ahora bien, aún quedaba por determinar si, en esta situación, las medidas tomadas con respecto al niño —en particular su retirada de los demandantes y su entrega en acogida por otra familia — podían ser consideradas proporcionadas; en particular, quedaba por ver si los intereses del niño fueron tomados en consideración de manera suficiente por las autoridades italianas. A ese respecto, el TEDH sostuvo la opinión de que las referencias al orden público (como fin legítimo) no pueden ser consideradas como que confieren carta blanca para cualquier medida, ya que el Estado tiene la obligación de tomar en consideración el interés superior del menor, con independencia de la naturaleza del vínculo parental, genético o de otro tipo ${ }^{25}$. En este caso

22 Caso Paradiso y Campanelli c. Italia, STEDH de 27 de enero de 2015 (Sala), demanda núm. 25358/12, párr. 74; caso Wagner y J.M.W.L contra Luxemburgo, STEDH de 6 de octubre de 2011, demanda núm. 43490/08, párrs. 133-134; caso Mennesson c. Francia, STEDH de 26 de junio de 2014, demanda núm. 65192/11, párr. 81; caso Labassee c. Francia, STEDH de 26 de junio de 2014, demanda núm. 65941/11, párr. 60.

23 Caso Paradiso y Campanelli c. Italia, STEDH de 27 de enero de 2015 (Sala), demanda núm. 25358/12, párr. 76. De conformidad con la legislación rusa, al menos uno de los padres de intención debía tener un vínculo genético con el niño gestado por sustitución. En este caso, la empresa privada que preparó todo compró gametos y óvulos de donantes anónimos, con lo cual ese embrión (fecundado in vitro y alojado en la madre gestante, pasaba ser «el embrión» de los padres de intención. De hecho el padre de intención estaba convencido de ser el padre biológico del niño y no se ha podido probar que actuase de mala fe.

24 Caso Paradiso y Campanellic. Italia, STEDH de 27 de enero de 2015 (Sala), demanda núm. 25358/12, párr. 77.

25 Caso Paradiso y Campanelli c. Italia, STEDH de 27 de enero de 2015 (Sala), demanda núm. 25358/12, párr. 80. Confirmando su reciente jurisprudencia en este punto: el retirar un niño de una familia es una medida que solo puede estar justificada si persigue como fin el proteger al nińo frente a un peligro inmediato que lo amenaza: caso $Y$. C. contra Reino Unido, STEDH de 13 de marzo de 2012, demanda núm. 4547/10, párrs. 133 a 138; caso Pontes c. Portugal, STEDH de 10 de abril de 2012, demanda núm. 19554/09, párrs. 74 a 80. 
concreto, la decisión de las autoridades italianas de retirarles el niño nacido mediante gestación por sustitución, no podría considerarse una medida justificada, en opinión de la Sala del TEDH, por las razones que enumera en los párrs. 82 a 85 de su sentencia de 27 de enero de 2015:

— En primer lugar, el alegar que el nińo habría desarrollado lazos emocionales más estrechos con sus padres de intención en caso de que le hubiera permitido estar más tiempo con ello no justifica su retirada.

- Con respecto a la causa penal traída contra los demandantes, la Sala del TEDH constató que el Tribunal de Apelación italiano había mantenido, que no era necesario esperar a su resultado ya que la responsabilidad penal de los demandantes era insignificante, de manera que las sospechas que pesaban sobre los demandantes eran también insuficientes para justificar la medida controvertida.

- La Sala del TEDH observó que los demandantes, que habían sido catalogados como aptos para adoptar en diciembre de 2006, cuando recibieron la autorización para adoptar, fueron hallados incapaces de criar y amar al niño solo sobre la base de que se habían saltado el procedimiento de adopción, sin que los tribunales italianos hubieran encargado ningún informe de expertos al respecto.

- Por último, la Sala del TEDH señaló que el niño recibió una nueva identidad a partir de abril de 2013, lo que significa que no tuvo identidad oficial durante más de dos años. Sin embargo, es necesario asegurar que un niño no esté en situación desventajosa por el hecho de que haya nacido de una madre que lo haya gestado por sustitución, especialmente en términos de ciudadanía o de identidad, que son de crucial importancia (como prevé el art. 7 de la Convención de Naciones Unidas sobre los Derechos del Niño de 20 de noviembre de 1989).

En consecuencia, no estando la Sala del TEDH convencida de las razones que motivaron a las autoridades italianas para concluir la necesidad de que el niño pasara a los cuidados de los servicios sociales, concluyó que fallaron a la hora de respetar un justo equilibrio entre los intereses en presencia, causando una violación del art. 8 del Convenio ${ }^{26}$.

Llamado a conocer en apelación sobre el caso por el Estado demandado en virtud del art. 43 del CEDH, la Gran Sala del TEDH adoptó, el 24 de enero de 2017, una sentencia, por una mayoría de once votos contra seis, en la

26 Caso Paradiso y Campanellic. Italia, STEDH de 27 de enero de 2015 (Sala), demanda núm. 25358/12, párr. 87. 
que discrepaba frontalmente con el fallo dictado por la Sala en el mismo caso el 27 de enero de 2015, y en la que decidió que las autoridades italianas no fueron responsables de una violación del art. 8 del Convenio. En términos muy simplificados y con independencia de que se desarrolle a continuación el análisis del razonamiento seguido por la Gran Sala en este caso, se puede explicar esta diferencia de criterio en el hecho de que para la Gran Sala habría sido determinante la inexistencia de un vínculo biológico entre el padre de intención y el menor nacido en virtud de un contrato de gestación por sustitución. La falta de ese vínculo - presente en los casos Labassee y Menesson c. Francia (SSTEDH de 26 de junio de 2014) y Foulon y Bouvet c. Francia (STEDH de 21 de julio de 2016) - habría llevado a la Gran Sala del TEDH a realizar dos importantes consideraciones: la inexistencia de una vida familiar de facto $^{27}$ y la no condición de víctima del menor concernido en relación con el art. 8 del Convenio Europeo al no ser considerado parte demandante ${ }^{28}$. Esas dos importantes consideraciones le van a permitir marcar una separación con los casos contra Francia ya señalados, en los que sí constató una violación del art. 8 del Convenio sufrido por menores nacidos mediante un contrato de gestación por sustitución en el extranjero y cuya filiación legal se impedía por consideraciones de orden público.

Como es sabido, los derechos protegidos en los arts. 8 a 11 del CEDH son derechos de protección relativa en la medida en que pueden ser objeto de restricción en su ejercicio, en circunstancias normales, siempre que se cumplan las condiciones previstas en el párrafo segundo común a los mismos; esto es, que se trate de una injerencia que esté prevista en la ley y que sea una medida necesaria en una sociedad democrática para alcanzar un fin legítimo (García San José, 2002: 251). El núcleo del análisis que el Tribunal Europeo realiza sobre la compatibilidad de una injerencia en los derechos reconocidos a los particulares en estos arts. 8 a 11 con las obligaciones asumidas por los Estados que son parte en el mismo reside en comprobar si la injerencia en cuestión puede o no ser considerada «necesaria».

La necesidad en cada caso concreto va a depender de dos factores. De una parte, del margen de apreciación reconocido a los Estados en esa materia - que será mayor o menor en virtud, por ejemplo, de que exista un consenso a nivel europeo sobre la cuestión controvertida-. De otra parte, la necesidad de una injerencia en el disfrute de los derechos protegidos en el Convenio

Párrs. 149, 153-154, 157-158 de la Sentencia de 24 de enero de 2017 (Gran Sala) del TEDH en el caso Paradiso y Campanelli c. Italia, demanda núm. 25358/12.

28 Párrs. 132, 135 y 208 de la Sentencia de 24 de enero de 2017 (Gran Sala) del TEDH en el caso Paradiso y Campanelli c. Italia, demanda núm. 25358/12. 
estará en función de la naturaleza del derecho afectado por la injerencia y de su importancia para el particular demandante (García San José, 2002: 253254). En todo caso, el control europeo va a exigir de parte del Tribunal Europeo verificar si las autoridades del Estado demandado aportan razones relevantes y suficientes para justificar la injerencia en el ejercicio de los derechos protegidos y que motiva la demanda sobre la que debe pronunciarse. Grosso modo puede decirse que si el Tribunal Europeo reconoce un amplio margen de apreciación a las autoridades nacionales por tratarse, por ejemplo, de una cuestión que afecta a cuestiones morales sensibles y sobre las que cada Estado mantiene una opinión propia sin que pueda reconocerse un consenso a nivel europeo - como es el caso del comienzo de la vida y la consideración jurídica del ser humano en formación ${ }^{29}$-, entonces será más fácil para el Estado demandado convencer al Tribunal de la relevancia y suficiencia de «sus razones» para haber actuado del modo en que lo hizo.

Sin embargo, la amplitud del margen de apreciación nacional en ocasiones no es suficiente por sí solo para convencer al Tribunal Europeo del carácter necesario y proporcionado de una injerencia, en especial cuando la injerencia controvertida afecta al núcleo duro del derecho protegido en el Convenio o es un derecho de una importancia esencial para el particular que sufre tal injerencia ${ }^{30}$. Así, dentro del derecho a la vida privada (art. 8 del Convenio) ocupa una posición privilegiada el derecho a la intimidad ${ }^{31}$, o el derecho a la identidad personal del que forma parte necesariamente indisoluble el derecho a la nacionalidad y a determinar la filiación legal tratándose de un menor nacido en el extranjero mediante un contrato de gestación por sustitución legalmente celebrado en un país extranjero y cuyos efectos no se reconocen en el país del que son nacionales sus padres de intención ${ }^{32}$. Gráficamente

29 STEDH (Gran Sala) de 8 de julio de 2004 en el caso VO c. Francia, demanda núm. 53924/00, párr. 84. STEDH (Sala) de 7 de marzo de 2006, párrs. 54 a 56 y (Gran Sala) de 10 de abril de 2007, demanda núm. 6339/05, párrs. 45 a 47, ambas en el caso Evans c. Reino Unido. STEDH de 27 de agosto de 2015, párr. 169 en el caso Parrillo c. Italia, demanda núm. 46470/11.

30 Como es el caso de las sanciones — por pequeñas que sean — impuestas a periodistas y que podrían desmotivarlos a la hora de cumplir su importante papel de control en una sociedad democrática. STEDH de 23 de agosto de 1994, caso Jersild c. Dinamarca, demanda núm. 15890/89, párr. 31.

31 Casos Dudgeon y Norris c. Irlanda, demandas núm. 7525/76 y 10581/83, SSTEDH de 22 de octubre de 1981 y de 26 de octubre de 1988, respectivamente.

32 Párrs. 96 a 98 de la STEDH de 26 de junio de 2014 en el caso Mennesson c. Francia, demanda núm. 65192/11. Párrs. 79 a 81 de la STEDH de 26 de junio de 2014, caso Labassee c. Francia, demanda núm. 65941/11. 
puede ser descrito con la imagen de una palanca que, sobre un punto de apoyo fijo, pretende elevar un bloque cuyo peso va a depender de la naturaleza del derecho afectado y de su importancia para el particular. La fuerza a aplicar para elevar ese peso va a depender, además del propio cuerpo a mover, de la longitud de la palanca (el equivalente al margen de apreciación nacional), siendo así que a mayor longitud de la palanca, menor fuerza será necesario aplicar a tal fin (razones relevantes y suficientes con las que convencer al Tribunal Europeo).

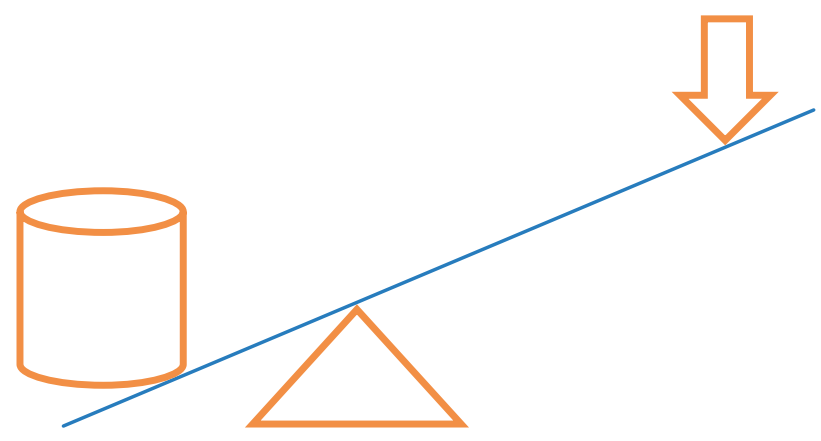

De este modo, el razonamiento que va a desarrollar la Gran Sala del Tribunal Europeo en el caso Paradiso y Campanelli c. Italia parte de la previa constatación de la inexistencia de un consenso europeo en los Estados que son parte en el Convenio con respecto a la gestación por sustitución y sus efectos legales cuando es realizada en el extranjero ${ }^{33}$. Esta constatación implica, en la práctica, aceptar un amplio margen de apreciación a las autoridades nacionales para valorar qué medidas debían aplicarse en caso para alcanzar el fin legítimo perseguido (la defensa del orden público). Asimismo, la Gran Sala asume otra importante premisa para desarrollar su razonamiento: la ausencia de un derecho de

33 Párrs. 182 y 194 de la sentencia de 24 de enero de 2017 (Gran Sala) del TEDH en el caso Paradiso y Campanelli c. Italia, demanda núm. 25358/12: «El tribunal advierte que los hechos del caso tocan cuestiones éticamente sensibles —adopción, la custodia de un niño, maternidad por sustitución y reproducción medicamente asistidarespecto de las cuales los Estados miembros (del Consejo de Europa) disfrutan de un amplio margen de apreciación [...]. Cuando no existe un consenso entre los Estados miembros del Consejo de Europa, tanto en lo relativo a la importancia de los intereses en presencia, como en relación al mejor modo de protegerlos, particularmente cuando el Caso afecta a cuestiones éticas y morales sensibles, el margen de apreciación será más amplio», (la traducción del original en inglés es nuestra). 
importancia esencial para los demandantes — los padres de intención y el menor, a quien llega incluso a considerar como no parte demandante en el caso ${ }^{34}$. Al tratarse de una injerencia en el derecho al respeto de la vida privada de los padres de intención y no de una injerencia en su derecho al respeto de su vida familiar - de hecho, la Gran Sala va a considerar que no se daba una vida familiar de facto entre ellos y el menor ${ }^{35}$ — la relevancia del derecho afectado para el demandante se diluye (no está en juego el derecho a la identidad y al reconocimiento de una relación legal paterno-filial en cuanto al menor). Para alcanzar sendas constataciones sobre las que construir su razonamiento, la Gran Sala del TEDH en el Caso Paradiso y Campanelli c. Italia se apoyó, de nuevo, en la inexistencia del vínculo biológico entre los padres de intención y el menor concernido.

El razonamiento seguido por la Gran Sala del Tribunal Europeo de Derechos Humanos no fue unánimemente compartido por los jueces que la componían, de manera que la sentencia fue adoptada por votación imponiéndose una mayoría de once jueces sobre una minoría de seis. De estos últimos, cinco firmaron una opinión disidente conjunta ${ }^{36}$ en la que defendían que, en las circunstancias del caso, el único fallo posible debía haber sido el declarar la responsabilidad del Estado italiano por la violación del art. 8 del Convenio, coincidiendo con el fallo alcanzado por la Sala del Tribunal Europeo en su sentencia de 27 de enero de 2015. Para estos jueces de la minoría, dos razones estrechamente interconectadas debieron haber sido tenidas en cuenta por la mayoría: de una parte, la existencia de una vida familiar de facto en las circunstancias del caso, al entender que la inexistencia del vínculo biológico entre el padre de intención y el menor no sería tan determinante como la actitud de las partes; en especial, el hecho de que la escasa duración de la cohabitación entre el menor y los padres de intención no sería imputable a aquellos, sino a las autoridades italianas, que la cortaron de manera radical al considerar que el menor estaba en situación de abandono ${ }^{37}$. De otra parte, los jueces que firman la opinión disidente conjunta al fallo de la mayoría de la Gran Sala negaron que las autoridades italianas hubieran respetado un justo equilibrio entre los diversos intereses en juego al no haber tomado en cuenta el interés

34 Párrs. 132, 135 y 208 de la sentencia de 24 de enero de 2017 (Gran Sala) del TEDH en el caso Paradiso y Campanelli c. Italia, demanda núm. 25358/12.

35 Párrs. 132-133 y 198 de la sentencia de 24 de enero de 2017 (Gran Sala) del TEDH en el caso Paradiso y Campanelli c. Italia, demanda núm. 25358/12.

36 Los jueces Lazarova Trajkovska, Bianku, Laffranque, Lemmens y Grozev.

37 Puntos 4 y 5 del voto disidente conjunto de los jueces Lazarova Trajkovska, Bianku, Laffranque, Lemmens y Grozev en la sentencia de 24 de enero de 2017 (Gran Sala) del TEDH en el caso Paradiso y Campanelli c. Italia, demanda núm. 25358/12. 
superior del menor. En su opinión, la retirada del niño de sus padres de intención se habría hecho exclusivamente por consideraciones legales, esto es, de cumplimiento con el orden público y para desmotivar a otros padres potenciales italianos de proceder de similar modo al que ellos habían actuado ${ }^{38}$.

\section{REPERCUSIONES EN EL ORDENAMIENTO JURÍDICO ESPAÑOL DEL ACTIVISMO Y DE LA AUTOLIMITACIÓN JUDICIAL DEL TRIBUNAL EUROPEO DE DERECHOS HUMANOS EN RELACIÓN CON LA GESTACIÓN POR SUSTITUCIÓN.}

Sin duda, la normativa española que prohíbe la gestación por sustitución —el art. 10 de la Ley 14/2006, de 26 de mayo, sobre técnicas de reproducción humana asistida ${ }^{39}$ - es conforme con el principio del respeto de la dignidad de cualquier ser humano individualmente considerado, en virtud del cual se prohíbe el aprovechamiento económico del cuerpo humano y de partes del mismo $^{40}$. Encuentra además respaldo normativo a nivel supranacional en el art. 3 de la Carta de Derechos Fundamentales de la Unión Europea ${ }^{41}$. Sin

38 Puntos 11 y 12 del voto disidente conjunto de los jueces Lazarova Trajkovska, Bianku, Laffranque, Lemmens y Grozev en la sentencia de 24 de enero de 2017 (Gran Sala) del TEDH en el caso Paradiso y Campanelli c. Italia, demanda núm. 25358/12.

39 «Artículo 10. Gestación por sustitución. 1. Será nulo de pleno derecho el contrato por el que se convenga la gestación, con o sin precio, a cargo de una mujer que renuncia a la filiación materna a favor $\mathrm{dl}$ contratante o de un tercero. 2. La filiación de los hijos nacidos por gestación de sustitución será determinada por el parto. 3. Queda a salvo la posible acción de reclamación de la paternidad respecto del padre biológico, conforme a las reglas generales».

40 Es el caso, por ejemplo, del art. 21 del «Convenio para la protección de los derechos humanos y la dignidad del ser humano con respecto a las aplicaciones de la biología y la medicina» (Convenio de Oviedo de 4 de abril de 1997), que vincula a España desde el 1 de enero de 2000. BOE de 20 de octubre de 1999, corregido en BOE de 11 de noviembre de 1999.

41 Publicada en el Diario Oficial núm. C 303, de 14 de diciembre de 2007. «Artículo 3. Derecho a la integridad de la persona: 1 . Toda persona tiene derecho a su integridad física y psíquica. 2. En el marco de la medicina y la biología se respetarán en particular: a) el consentimiento libre e informado de la persona de que se trate, de acuerdo con las modalidades establecidas por la ley; b) la prohibición de las prácticas eugenésicas, en particular, las que tienen como finalidad la selección de las personas; c) la prohibición de que el cuerpo humano o partes del mismo en cuanto tales se conviertan en objeto de lucro». 
embargo, contrasta con el hecho de que España se ha convertido en un destino favorito en el turismo reproductivo a escala mundial. Gracias a la alta calidad de los tratamientos médicos ofertados y al amparo de una legislación muy permisiva, las clínicas españolas de procreación asistida se han convertido en referente mundial para aquellas mujeres que desean someterse a tratamientos de fertilidad. El secreto de este éxito está en la abundancia y calidad de los óvulos donados... a cambio de una cantidad de 1200 euros por las molestias derivadas de la estimulación hormonal programada. Frente a la prohibición de la gestación por sustitución, resulta llamativo el laissez-faire seguido por las autoridades espańolas — tanto en el ámbito estatal como autonómico- en esta cuestión que no solo afecta a la dignidad intrínseca de cada una de las donantes de óvulos — chicas jóvenes de España e inmigrantes de otros países quienes se ven obligadas por necesidades económicas a comercializar partes de su cuerpo-, sino que, más grave aún, supone un riesgo para su salud en el futuro provocado por el exceso de estimulación hormonal con el fin de producir óvulos «en serie» (Alkorta Idiákez, 2008: 38).

Los avances en las técnicas de reproducción asistida —en relación con la donación de óvulos o la oferta de vientres de alquiler- invitan a reflexionar sobre el impacto que las tecnologías reproductivas pueden tener sobre las mujeres del norte y del sur del mundo (Fanlo Cortés, 2017: 46) y, en cierto modo, resulta paradójico respecto a los avances de la tecnociencia en el marco de la desigualdad norte/sur que la antigua conceptualización de la mujer como vasija reproductora (Nuño Gómez, 2016: 693) reaparezca ahora deslocalizada en los países del sur global (Puleo, 2017: 183). En este sentido, parece lógico que se denuncie desde un importante sector doctrinal que la maternidad por subrogación no respeta la dignidad de la madre portadora, no solo porque esta queda reducida únicamente a su dimensión corporal, como un algo disponible y susceptible de transacción comercial (Aparisi Miralles, 2017: 172). Incluso cuando se invoca la subrogación altruista ha de reconocerse que la legalización de la maternidad subrogada altruista se lleva a cabo en virtud de las exigencias de los padres intencionales y no por una altruista oferta de las madres portadoras (Albert Márquez, 2017, 195).

En lo relativo a la gestación por sustitución - $\mathrm{y}$ en lo que respecta a España-, grosso modo, el recorrido jurídico que hasta la fecha ha tenido esta cuestión viene marcado por los siguientes hitos: a raíz del recurso planteado por unos ciudadanos españoles contra la negativa del cónsul general de España en California de permitir la inscripción en el registro consular de un hijo nacido mediante un contrato de gestación por sustitución -invocando su incompatibilidad que el referido art. 10 de la Ley 14/2006, de 26 de mayo, sobre técnicas de reproducción humana asistida, a pesar de que dicha técnica 
de gestación por sustitución estaba permitida en el estado de California—, la Dirección General de los Registros y del Notariado de España dictó una resolución el 18 de octubre de 2009 denegando la inscripción en el Registro Civil a los hijos nacidos mediante contratos de gestación por sustitución en el extranjero (Camarero González, 2012: 1-9).

Agotada la vía administrativa, los interesados acudieron a la vía judicial, dictándose sentencia del Juzgado de Primera Instancia núm. 15 de Valencia, de 15 de septiembre de 2010, confirmando la denegación de solicitud de inscripción. Sin embargo, mediante instrucción de la Dirección General de los Registros y del Notariado, de 5 de octubre de 2010, se permitió la inscripción de esta filiación siempre que viniera acompañada de una resolución judicial extranjera dictada en procedimiento no litigioso (Calvo y Carrascosa, 2011: 250-261; Vela Sánchez, 2011: 1-17). Como se indicaba en su exposición introductoria, se pretendía con ella dotar de plena protección jurídica el interés superior del menor al tiempo que se valoraban debidamente otros intereses presentes en este tipo de contratos de gestación por sustitución, en especial la protección de las mujeres que se prestan a dicha técnica de reproducción renunciando a sus derechos como madres. Así, a fin de garantizar la protección de dichos intereses, la instrucción de 5 de octubre de 2010 establecía como requisito previo para la inscripción de los nacidos mediante gestación por sustitución la presentación ante el encargado del Registro Civil de una resolución judicial dictada por tribunal competente. Con ello - se insistía en el preámbulo de la instrucción-, «se protege el interés del menor, facilitando la continuidad transfronteriza de una relación de filiación declarada por Tribunal extranjero, siempre que tal resolución sea reconocida en España» y al mismo tiempo, «la presente instrucción incorpora la doctrina plenamente consolidada por el Tribunal Supremo» ${ }^{42}$.

42 En virtud de dicha doctrina y aplicada al supuesto concreto de la filiación de los nacidos mediante gestación por sustitución, establece la disposición primera, apdos. 1 y 2 de esta instrucción, que si el encargado del Registro Civil considera que la resolución extranjera ha sido dictada en el marco de un procedimiento jurisdiccional de naturaleza contenciosa, debe denegar la inscripción de la resolución al requerir previamente el exequátur de esta conforme a lo previsto en el art. 955 de la LEC 1881 tras la reforma operada por la Ley 62/2003, de 30 de diciembre, de medidas fiscales, administrativas y del orden social. Ahora bien, si el encargado del Registro Civil estima que la resolución extranjera tiene su origen en un procedimiento análogo a uno español de jurisdicción voluntaria, entonces solo controlará incidentalmente si la resolución puede ser reconocida en Espańa como requisito previo a su inscripción. Lógicamente, en los casos en los que se solicite la inscripción del nacido en el extranjero mediante gestación por sustitución sin que se 
Este cambio de criterio de la Dirección General de los Registros y del Notariado fue confirmado por la sentencia de la Audiencia Provincial de Valencia (resolviendo en apelación), de 23 de noviembre de 2011, dando la razón a los demandantes en su pretensión de inscripción registral para su hijo (Vela Sánchez, 2012: 1-15). Sin embargo, el Tribunal Supremo, en su sentencia de 6 de febrero de 2014, núm. 853/2013, resolviendo el recurso de casación planteado por la Abogacía del Estado en este caso, revocó la autorización de inscripción en el Registro Civil español reconocida a los demandantes por la sentencia de la Audiencia Provincial de Valencia ${ }^{43}$. Días después, por medio de una circular de 11 de julio, la Dirección General de los Registros y del Notariado se ratificó en lo manifestado en su instrucción de 5 de octubre de 2010 a la luz de las sentencias del Tribunal Europeo de Derechos Humanos, de 26 de junio de 2014, en los casos Mennesson y Labassee c. Francia ${ }^{44}$. Sin embargo, la alegría de los demandantes duraría poco al conocer el auto del Tribunal Supremo de 2 de febrero de 2015, dictado en el incidente de nulidad de actuaciones formulado contra la sentencia de 6 de febrero de 2014, confirmando su sentencia de 6 de febrero de 2014, desdiciendo a la Dirección General de los Registros y del Notariado y negando cualquier incidencia en el ordenamiento jurídico español de las sentencias del Tribunal Europeo de Derechos Humanos en los casos Menesson y Labassee c. Francia ${ }^{45}$.

Resulta interesante conocer los argumentos de la mayoría de magistrados del Tribunal Supremo en este auto de 2 de febrero de $2015^{46}$, así como la opinión defendida por los cuatro magistrados en su voto particular contra dicho

presente una resolución que determine la filiación, reconocible incidentalmente o por exequátur, el encargado del Registro debe denegar la inscripción previendo expresamente la disposición segunda de la instrucción de 5 de octubre de 2010, que «en ningún Caso se admitirá como título apto para la inscripción del nacimiento y filiación del nacido, una certificación registral extranjera o la simple declaración, acompañada de certificación médica relativa al nacimiento del menor en la que no conste la identidad de la madre gestante».

43 Sobre la misma véase: De Torres Perea (2014: 1-17); García Alguacil (2014: 79-110); Paniza Fullana (2014: 59-67); Vela Sánchez (2014a: 1-15).

44 Sobre las mismas véase: Durán Ayago (2014: 280-282); Lamm (2014: 43-50); Flores Rodríguez (2014: 1-6); Vela Sánchez (2014b: 1-13).

45 Para un estudio detallado de todas las cuestiones planteadas ante el TS y resueltas por este en su sentencia de 6 de febrero de 2014, véase Calvo Caravaca y Carrascosa González (2017).

46 Los magistrados Rafael Sarazá Jimena (ponente), Francisco Marín Castán, Antonio Salas Carceller, Ignacio Sancho Gargallo, Francisco Javier Orduña Moreno, Eduardo Baena Ruiz y Xavier O’Callaghan Muñoz. 
auto $^{47}$. En su auto de 15 de febrero de 2015, el Tribunal Supremo se pronunció sobre dos cuestiones: sobre la pretendida vulneración de sus derechos fundamentales causada por la su sentencia de 6 de febrero de 2014, en primer lugar, y sobre la influencia de las sentencias del TEDH sobre la cuestión litigiosa, en segundo lugar. Contrariamente al orden de análisis seguido por el Tribunal Supremo, la cuestión relevante - y determinante para el sentido del fallo- es en mi opinión la segunda. El Tribunal Supremo niega cualquier repercusión de la jurisprudencia del TEDH sobre la sentencia del Tribunal Supremo de 6 de febrero de 2014, sobre la base de una interpretación de dichas sentencias en los casos Labassee y Mennesson que el tiempo ha venido a dar por buena. En concreto, argumentaba el Tribunal Supremo que la cuestión decisiva y lo determinante para la relación de filiación, esencial para determinar la identidad del menor — tal como había reconocido el TEDH—, era la filiación biológica y el establecimiento de lazos familiares como consecuencia de la existencia de un núcleo familiar de facto formado por los menores, el padre biológico y su cónyuge ${ }^{48}$.

A partir de esta situación de parentesco biológico en los casos contra Francia decididos por el TEDH que no se daba en el supuesto de los demandantes valencianos, la mayoría del Tribunal Supremo se basaba en que a diferencia del sistema jurídico francés, que cerraba todas las puertas al establecimiento de la filiación de los nińos respecto de los padres comitentes en supuestos de contratos de gestación por sustitución, el ordenamiento jurídico español ofrecía varias salidas al progenitor intencional que es además biológico y a su cónyuge por los mecanismos ordinarios del Código Civil (arts. 176.2 y 177.2). Si el fallo de la Gran Sala del TEDH en su sentencia de 24 de enero de 2017 en el caso Paradiso y Campanelli c. Italia fuera distinto al que es, sería de interés recordar la siguiente afirmación extraída del voto particular de los cuatro magistrados del Tribunal Supremo en el auto de referencia, que no pasa de ser anecdótica y reflejo, una vez más, de que la historia la escriben los vencedores:

Se va a cuestionar únicamente el pronunciamiento que aleja dichas sentencias de la nuestra y que autoriza, a nuestro juicio, a decretar la nulidad que se niega en el auto atendiendo a los principios que resultan de todas ellas estando como están en cuestión intereses similares que exigen la protección de derechos fundamentales que hubieran exigido una protección más coherente de estos principios con una realidad innegable, como es la de los vientres de alquiler, y de

47 Los magistrados José Ramón Ferrándiz Gabriel, José Antonio Seijas Quintana, Francisco Javier Arroyo Fiestas y Sebastián Sastre Papiol.

48 FJ 6 del auto del TS de 15 de febrero de 2015. 
unos nińos que están creciendo en un entorno familiar, social y económico, con independencia de la nulidad del contrato que propició su nacimiento. En definitiva, con el interés de los menores, niños de carne y hueso, que no están en condiciones de recibir la protección especial que merecen sus derechos, sus necesidades y sus problemas desde su estancia en España ${ }^{49}$.

Así pues, en opinión de los magistrados discrepantes con la mayoría, la diferencia entre los supuestos francés y español no sería suficiente para negar a los demandantes el amparo solicitado, a la luz de la esencia de la ratio decidendi del TEDH en la que el interés superior del menor ocupa un lugar central, más allá de cualquier consideración de orden público que pueda esgrimirse por Francia o por cualquier otro Estado. Como recuerdan los magistrados discrepantes con el auto dictado, las salidas previstas en el Código Civil para los padres comitentes y que sustentan el voto de la mayoría de los magistrados de la Sala de lo Civil del Tribunal Supremo no se habían materializado aún, de manera que se creaba una incertidumbre inquietante en cuanto a la situación de los menores - a la que se refería el TEDH en sus sentencias de 26 de junio de 2014 (Labassee y Menesson c. Francia) y sobre la que volvió a insistir en su sentencia de 27 de enero de 2015 (Paradiso y Campanelli c. Italia) anterior al auto del Tribunal Supremo y que, por tanto, conocían o debían conocer: lo que es necesario es que un niño no se vea perjudicado por el hecho de que haya sido traído al mundo por una madre subrogada, comenzando por la ciudadanía o la identidad, que revisten una importancia primordial.

Desde el punto de vista de estos cuatro magistrados del Tribunal Supremo, no es solo que el problema afecte además de a los padres, a los hijos. Es, por encima de todo, que la aproximación debe hacerse desde el interés superior del menor ${ }^{50}$. En ese sentido, en su opinión —que podría o no compartirse en su momento, pero que hoy por hoy no es defendible a la luz de la sentencia de 24 de enero de 2017, de Gran Sala en el caso Paradiso y Campanelli c. Italia - más allá de las diferencias que puedan existir entre las sentencias de 26 de junio de 2014 dictadas por el TEDH en los casos Labassee y Menesson c. Francia y la que dictó el Tribunal Supremo el 6 de febrero de 2014:

La solución alcanzada por la mayoría no ha realizado una adecuada ponderación de los bienes jurídicos en conflicto que tome en consideración primordial,

49 Punto II del voto particular de los magistrados José Ramón Ferrándiz Gabriel, José Antonio Seijas Quintana, Francisco Javier Arroyo Fiestas y Sebastián Sastre Papiol.

50 Punto III del voto particular de los magistrados José Ramón Ferrándiz Gabriel, José Antonio Seijas Quintana, Francisco Javier Arroyo Fiestas y Sebastián Sastre Papiol. 
no sólo el interés superior de los menores, que fundamenta en lo sustancial las resoluciones del TEDH, sino la incertidumbre jurídica que la situación genera y seguirá generando en tanto no se dé respuesta a su solicitud de inscripción, y, en definitiva, el modelo de protección que resulta de todas ellas desde la óptica actual de los derechos humanos y de una legislación desbordada por una realidad que deja sin contenido las estructuras lógicas y formales del derecho, con el grave efecto de retrasar una filiación que podía haber sido ya fijada definitivamente y sin inconveniente alguno para nuestro ordenamiento jurídico que, de una forma u otra, lo está admitiendo a través de vías verdaderamente singulares como son las circulares o las instrucciones de la Dirección General de los Registros y del Notariado que han terminado por convertir la excepción de orden público en una cuestión meramente formal (punto III de su voto particular).

\section{CONCLUSIONES}

Al finalizar estas páginas varias son las conclusiones alcanzadas. En primer lugar, los contratos de gestación por sustitución son una realidad que plantea problemas jurídicos para los ciudadanos que los Estados no pueden desconocer. Una prohibición de estos en territorio nacional y de sus efectos jurídicos si se realizan en el extranjero no es la mejor solución aun cuando se invoquen razones de orden público y evitar actos en fraude de ley. La permisibilidad absoluta tampoco es la respuesta idónea, pues no todo lo que la ciencia permite es moralmente aceptable en una sociedad. Solo queda la vía de una regulación legal que sea equilibrada, tomando en consideración todos los intereses en juego, como se ha producido no hace mucho en relación con los bancos privados de sangre de cordón umbilical, que originalmente fueron prohibidos en Espańa para luego ser autorizados cumpliendo determinadas condiciones (Real Decreto Ley 9/2014, de 4 de julio, que sustituye al Real Decreto 1301/2006). Esa regulación legal es necesaria, urgente y posible siempre que se dé la voluntad política del legislador. En cualquier caso, la vida de las personas no se detiene por la inacción de las autoridades de un Estado, no regulando cuestiones que les afectan directamente. De manera que la brecha entre lo que es de hecho y de derecho crece a cada día que pasa.

En segundo lugar, la capacidad normativa de los Estados en su esfera interna está condicionada por las obligaciones internacionales asumidas en sus relaciones con otros Estados. Tratándose del contexto europeo, el legislador español ha de ser consciente de que además de que es Estado miembro de la Unión Europea, es Estado parte en el Convenio Europeo de Derechos Humanos, en cuya virtud debe asegurar el efectivo disfrute de los derechos y libertades humanos en el 
mismo recogidos. Más aún, al contar este convenio con un órgano propio de interpretación y aplicación, el Tribunal Europeo de Derechos Humanos, cada Estado parte debe cumplir las sentencias que le afecten (res iudicata inter partes) y tomar en consideración la ratio decidendi de aquellas que sin afectarle directamente recogen la doctrina de este tribunal internacional sobre algún derecho y libertad reconocido en el Convenio (res interpretata erga omnes). Así, la interpretación que el Tribunal Europeo ha realizado en su reciente jurisprudencia sobre el concepto de vida familiar de facto entre padres de intención y niños concebidos mediante gestación por sustitución — reconociendo esta siempre que se dé un vínculo biológico entre las partes - ha de ser tenida debidamente en cuenta.

Como tercera y última idea que puede concluirse de este estudio, cabe señalar que es necesario encontrar un equilibrio entre el derecho a la identidad de un menor como parte fundamental — de hecho, el núcleo duro- del derecho a la vida privada, incluyendo su derecho a ver reconocida su filiación legal y su nacionalidad, y las legítimas consideraciones de orden público que el legislador puede pretender hacer prevalecer sobre el eventual derecho de una persona a ser progenitor y a fundar una familia, acudiendo a terceros cuando biológicamente está impedido para ello. La aproximación desde los derechos fundamentales a la regulación de la gestación por sustitución, más allá de abogar por que el derecho asuma nuevas formas de familia conforme se producen los avances de la ciencia, lo que hace es llamar la atención sobre la necesaria aproximación integradora y transversal de todos los intereses enfrentados, respecto de los cuales el respeto de un justo equilibrio es indispensable. A día de hoy el equilibrio provisional está en considerar como compatible con el Convenio Europeo la negativa de las autoridades de un Estado a tomar en consideración los efectos legales de gestaciones por sustitución celebradas en el extranjero en ausencia de un vínculo biológico entre los padres de intención y los menores así concebidos. Ahora bien, nada permite creer que esta línea roja sea inamovible. Antes al contrario, la interpretación teleológica, activista y províctima que el Tribunal Europeo viene desarrollando desde sus comienzos permite aventurar que, más pronto que tarde, la existencia de tal vínculo perderá la relevancia que ahora tiene para constatar la existencia de una vida privada y familiar de facto que deba ser protegida, también, en el contexto de la gestación por sustitución.

\section{Bibliografía}

Albert Márquez, M. (2017). La explotación reproductiva de mujeres y el mito de la subrogación altruista: una mirada global al fenómeno de la gestación por sustitución. Cuadernos de Bioética, 28 (2), 177-198. 
Alkorta Idiakez, I. (2008). Human tissue and cells regulation in Spain: Looking at Europe to solve inner contradictions? Revista de Derecho y Genoma Humano, 29, 25-44.

Aparisi Miralles, A. (2017). Maternidad subrogada y dignidad de la mujer. Cuadernos de Bioética, 28 (2), 163-176.

Calvo Caravaca, A. y Carrascosa González, J. (2017). Gestación por sustitución y derecho internacional privado. Más allá del Tribunal Supremo y del Tribunal Europeo de Derechos Humanos. Cuadernos de Derecho Transnacional, 7 (2), 45-113.

Camarero González, G. (2012). Notas sobre la Resolución de la Dirección General de los Registros y del Notariado de 18 de febrero de 2009, en un caso de gestación por sustitución. Diario La Ley, 7910, 1-9.

Carrillo Salcedo, J. A. (2003). El Convenio Europeo de Derechos Humanos. Madrid: Tecnos.

Davis, E. (2012). The Rise of Gestational Surrogacy and the Pressing Need for International Regulation. Minnesota Journal of International Law, 1, 120-141.

De Torres Perea, J. M. (2014), Comentario de la STS de 6 de febrero de 2014 sobre maternidad por sustitución desde la perspectiva del interés del menor. Diario La Ley, 8281, 1-17.

Durán Ayago, A. (2014), Sentencias del Tribunal Europeo de Derechos Humanos, caso Mennesson c. France (núm. 65192/11) y caso Labassee c. France (núm. 65941/11) de 26 de junio de 2014: interés superior del menor y gestión por sustitución. Ars Iuris Salmanticensis, 2, 280-282.

Fanlo Cortés, I. (2017). Derechos reproductivos y libertad de las mujeres. Observaciones sobre el debate feminista. Revista de Derecho Privado, 32, 29-52.

Farnós Amorós, E. (2015). La reproducción asistida ante el Tribunal de Estrasburgo: margen de apreciación v. necesidad de armonización. Boletín del Ministerio de Justicia, (monográfico) 2179, 175-202.

Flores Rodríguez, J. (2014). Vientres de alquiler: más cerca de su reconocimiento legal en Europa. Comentario a la STEDH de 26 de junio de 2014, recurso núm. 65192/11. Diario La Ley, 8363, 1-6.

García Alguacil, M. J. (2014). ¿ Incoherencia legislativa o despropósito judicial?: a propósito de la STS de 6 de febrero de 2014. Revista Doctrinal Aranzadi Civil-Mercantil, 3, 79-110.

García San José, D. (2002). Ruido nocturno e insomnio: los derechos a la vida privada y familiar y al respeto del domicilio frente al interés general de los vuelos de aviones durante la noche. Revista Española de Derecho Constitucional, 64, 239-260.

Iliadou, M. (2017). Surrogacy and positive obligations under the European Convention on Human Rights. Revista Española de Derecho Europeo, 62, 1-19.

Lamm, E. (2014). Gestación por sustitución. La importancia de las sentencias del Tribunal Europeo de Derechos Humanos y su impacto. Ars Iuris Salmanticensis, 2, 43-50.

Mahoney, P. (1990). Judicial activism and judicial self-restraint in the European Court of Human Rights: two sides of the same coin. Human Rights Law Journal, 11, 57-88.

Nuño Gómez, L. (2016). Una nueva cláusula del contrato sexual: vientres de alquiler. Isegoría, 55, 683-700.

Paniza Fullana, A. (2014). Gestación por sustitución e inscripción de la filiación en el Registro Civil español: la Sentencia del Tribunal Supremo de 6 de febrero de 2014. Revista Doctrinal Aranzadi Civil-Mercantil, 1, 59-67. 
Puleo, A. H. (2017). Nuevas formas de desigualdad en un mundo globalizado. El alquiler de úteros como extractivismo. Revista Europea de Derechos Fundamentales, 29, 165-184.

Rodríguez-Yong y Martínez Muñoz, K. (2010). El contrato de maternidad subrogada: la experiencia estadounidense. Revista de Derecho (Valdivia), 2, 59-81.

Saiz Arnaiz, A. (1999). La apertura constitucional al derecho internacional y europeo de los derechos humanos. El artículo 10.2 de la Constitución Española. Madrid: Consejo General del Poder Judicial.

Selma Penalva, A. (2014). Los nuevos retos de la prestación por maternidad ante los avances médicos en materia de reproducción asistida. Revista Bioderecho, 1, 1-12.

Vela Sánchez, A. J. (2011). La gestación por sustitución o maternidad subrogada: el derecho a recurrir a las madres de alquiler. Cuestiones que suscita la Instrucción de la DGRN de 5 de octubre de 2010, sobre régimen registral de la filiación de los nacidos mediante gestación por sustitución. Diario La Ley, 7608, 1-17.

Vela Sánchez, A. J. (2012). De nuevo sobre la regulación del convenio de gestación por sustitución o de maternidad subrogada en España. A propósito de la sentencia de la Audiencia Provincial de Valencia de 23 de noviembre de 2011. Diario La Ley, 7815, 1-15.

Vela Sánchez, A. J. (2014c). Los hijos nacidos de convenio de gestación por sustitución no pueden ser inscritos en el Registro Civil español. A propósito de la sentencia del Tribunal Supremo de 6 de febrero de 2014. Diario La Ley, 8279, 1-14.

Vela Sánchez, A. J. (2014d). Los hijos nacidos de convenio de gestación por sustitución "pueden" ser inscritos en el Registro Civil español. A propósito de las sentencias del Tribunal Europeo de Derechos Humanos de 26 de junio de 2014. Diario La Ley, 8415, 1-13. 